\title{
A Study of Evaluation of Immunoreactivity of c-erbB-2 and Histopathological Parameter in Esophageal Carcinoma
}

\author{
Dr. Anil Kumar Singh ${ }^{1}$, Dr. G. V. Manjunath ${ }^{2,}$ Dr. Suchitha $S^{3}$. \\ Dr. Karan Mahinderu ${ }^{4}$ Dr. Malvika Singh ${ }^{5}$ \\ ${ }^{1,2,3,4}$ Department of Pathology, JSS Medical College, Mysore \\ ${ }^{5}$ Department Of Microbiology, University College Of Medical Sciences, Shahadara, Delhi
}

\begin{abstract}
Abstrct
Background: Squamous cell carcinoma is commonest histologic variant of carcinoma of esophagus (ESCC). It is predominant in developing countries and usually has a poor prognosis, because of its advanced stage at the time of diagnosis. Understanding the prognostic factors helps in selection of the most appropriate surgical approach in order to select patient for target directed therapies. HER-2/neu (C-erbB-2), member of human epidermal growth factor receptors (EGFR) is important, as it plays a crucial role in therapeutic implications of esophageal carcinoma. Considering the importance of c-erbB-2 expression and its prognostic significance in esophageal cancer, this study was undertaken.

Result: Fifty cases of esophageal carcinoma including squamous cell carcinoma and adenocarcinoma studied showed M: F ratio of 1.9:1 with age ranging from 32 years to 80 years (mean age 59.1 years). There were $43(86 \%)$ cases of Squamous cell carcinoma with $65.1 \%$ positivity of which $10(20 \%)$ cases were poorly diffentiated with a positivity of $60 \%, 20(40 \%)$ cases were moderately diffentiated with a positivity of $65 \%$ and 09 (18\%) were well differentiated with a positivity of 55.6\% for c-erbB-2 staining. Seven (14\%) cases of adenocarcinoma with a positivity of $85.7 \%$ and four (08\%) cases of endoscopic biopsy have a positivity of $75 \%$ for c-erbB-2 staining.

Conclusion: Present study results illustrate that HER-2/neu(c-erbB-2) gene amplification is a influential prognostic indicator in ESCC. Therefore, additional studies with more cases including supplementary techniques are compelling to verify molecular alterations involved in tumor progression, thus assisting in the advancement of modern therapies for ESCC.
\end{abstract}

Keywords: Esophageal squamous cell carcinoma, Adenocarcinoma, HER-2/neu(c-erbB-2), Human epidermal growth factor receptors (EGFR)

\section{Introduction}

Squamous cell carcinoma is most frequent histologic type of cancer of esophagus (ESCC). ${ }^{1}$ It occurs predominantly in developing countries and generally has a poor prognosis, because it is usually in an advance stage at the time of diagnosis. ${ }^{2}$

The mortality rate is still high, despite the development of many therapeutic modalities in addition to surgical resection. ${ }^{3}$ Esophagectomy with lymph node dissection has significant mortality rate. Hence, it is important to understand the prognostic factors that determine the appropriate surgical approach in order to select patient for target directed therapies.

The family of epidermal growth factor receptors comprises four homologous molecules; EGFR (epidermal growth factor receptor), c-erbB-2, c-erbB-3 and c-erbB-4. Various reports have suggested that abnormal activation of kinase activity in these receptors has role in tumor development and progression in ESCC. ${ }^{4}$ Activation of these receptor induces cell migration and aggregation as well as hyperproliferation and epithelial cell differentiation. The importance of these receptors has been studied in many malignant neoplasms, mainly in breast carcinoma, leading to specific treatment to inactivate them. ${ }^{5}$

Studies have shown that c-erbB-2 oncogene situated on chromosome 17 is overexpressed and amplified in many tumor types and have compared these results with histopathological data and c-erbB-2 immunohistochemical reactivity by using tissue microarray and conventional slides. Amplification and overexpression of c-erbB-2 predict and especially poor prognosis in breast cancer. ${ }^{6}$

Overexpression or amplification does not occur in pre-stages of adenocarcinoma. This implies that HER-2/neu overexpression or amplification is a late event in the process of tumorogenesis in esophageal adenocarcinoma. ${ }^{7}$ TNM-stage, grade, depth of tumor invasion and the presence of lymph node metastases are unrelated to HER-2/neu overexpression or amplification. ${ }^{8}$ 
Therefore, HER-2/neu overexpression or amplification is related to a decrease in survival, but is not related to any pathological features. This cannot be explained by a biological mechanism, so perhaps HER-2/neu overexpression or amplification can be seen as an independent prognostic factor, which is not dependent on pathological features. ${ }^{9}$

Patients with locally advanced esophageal cancers have a poor prognosis when treated exclusively by surgical resection. Therefore, many investigators apply neoadjuvant treatment strategies in an effort to improve survival. $^{10}$

Epidermal growth factor receptor (EGFR, synonym: c-erbB-1) and c-erbB-2 (synonym: HER-2/neu) are members of the type I growth factor receptor gene family. ${ }^{11}$ The c-erbB-1 gene translates a $170 \mathrm{kDa}$ membrane protein. Under physiologic conditions, binding of epidermal growth factor (EGF) or transforming growth factor- $\alpha$ (TGF- $\alpha$ ) leads to receptor kinase activity and subsequently a complex cascade of events that can induce cellular proliferation. ${ }^{12}$ The c-erbB-2 gene encodes a $185 \mathrm{kDa}$ transmembrane glycoprotein (p185) having tyrosine kinase activity. ${ }^{13}$ Overexpression of c-erbB-1 or c-erbB-2 mRNA and/or protein has been implicated in the pathogenesis of various solid tumors including breast, ovarian, lung and esophageal cancers.

One of the genetic alterations observed in human tumors that are thought to be involved in the etiology and progression of the disease is gene amplification. Evidence for amplification has been obtained by cytogenetic analysis with the presence of dmins or homogeneously staining regions in metaphase spreads and by DNA hybridization studies using specific protooncogenes as probes. ${ }^{14}$ In the first case, the gene(s) amplified are of unknown sequence, whereas in the second, a number of tumors of common origin often exhibit consistent amplification of a known protooncogene. ${ }^{15}$ It has been postulated that increased levels of the protooncogene product (as a result of gene amplification or overexpression) may play a role in the development of the cancer.

We have recently observed dmins in gastric and lower esophageal adenocarcinomas providing evidence for gene amplification. ${ }^{16}$ Multiple copies of HER-2/neu, c-myc, and c-erbB have previously been reported in gastric and esophageal squamous cell carcinomas and adenocarcinomas of mixed histological types. $^{17}$

Considering the importance of c-erbB-2 expression and its prognostic significance in esophageal cancer, this study is undertaken to investigate its frequency of expression in esophageal cancer and correlate with grading and staging of esophageal cancer, wherever possible.

\section{Materials And Methods}

A total of 50 patients with esophageal carcinoma (esophageal squamous cell carcinoma and adenocarcinoma), with 35 cases of esophagectomy and 15 cases of endoscopic esophageal biopsy were studied retrospectively and prospectively between Jan 2010 and Aug 2015.

The following patient data were reviewed in esophagectomy specimens: age at diagnosis, gender, type of surgery, tumor location, tumor size, macroscopic appearance, histological type, tumor grade, depth of invasion, number of lymph nodes resected and number of lymph nodes with metastasis, whereas in endoscopic esophageal biopsy specimens: age at diagnosis, gender, tumor location and histological type were reviewed.

Non-neoplastic lesions and small cell carcinoma of the esophagus are excluded from the study.

\section{Histology And TNM Classification}

Tissue specimens were fixed in $10 \%$ of neutral buffered formalin for 24-48 hours and embedded in paraffin. Deparaffinzed sections were stained with hematoxylin and eosin. Tumors were classified according to WHO classification. Tumor (T), Node (N) and Metastasis (M) cancer staging system of the American Joint Committee of Cancer (AJCC), seventh edition, was followed for staging of the esophagectomy specimens.

\section{Immunohistochemical Staining}

Antigen retrieval was done by using sodium citrate buffer $(0.01 \mathrm{M} ; \mathrm{pH}, 6.0)$. The sections were incubated with primary antibody [Novacastra, Mouse Monoclonal Antibody: CB11,AM134-5ME] for 1 hour and washed with TBS for $2 \times 5 \mathrm{~min}$. External positive control tissue included sample of breast carcinomas positive for HER-2/neu. For negative controls, primary antibody was omitted and phosphate buffer saline was substituted. IHC analysis was done using the scoring scheme provided by the Hercep Test kit.

The following scoring system was used:

In endoscopic biopsies, any cell cluster with membranous staining will be considered as positive.

In resected specimens,

Score 0 is no membrane staining or $<10 \%$ of cells stained.

$1+$ is incomplete membrane staining in $>10 \%$ of the cells.

$2+$ is weak to moderate complete membrane staining $>10 \%$ of the cells.

$3+$ is strong and complete membrane staining in $>10 \%$ of the cells. 


\section{Statistical Analysis}

Statistical analysis was performed using the chi-square test to analyze association between HER-2/neu status and clinicopathological parameters. P value $<0.05$ were considered significant. The SPSS software, version 16.0 was used for data analysis.

\section{Result}

In the present study a total number of 50 esophageal carcinomas were evaluated out of which 35 were esophagectomy specimens and 15 were endoscopic esophageal biopsies.

Out of 50 cases, the maximum number of cases was in the age group of 51 to 60 and 61 to 70 years and the least number of cases were seen in the lesser than 31 to 40 age group. The youngest patient in our study was 32 year old and oldest was 80 year, with a mean age of 59.1years.

Out of 50 cases, $33(66 \%)$ were males and $17(34 \%)$ were females with a male to female ratio of 1.9:1. In terms of tumor location, $32(64 \%)$ of the tumors were located in middle $1 / 3^{\text {rd }}$ of esophagus, $13(26 \%)$ in lower $1 / 3^{\text {rd }}$ of esophagus, $01(02 \%)$ in upper $1 / 3^{\text {rd }}$ of esophagus and $04(08 \%)$ involving the gastro esophageal junction.

Based on the gross appearance, the tumors were classified into ulcerative, proliferative, infiltrative, ulceroproliferative, ulceroinfiltrative and diffusely infiltrative. Out of the 35 esophagectomy specimens, six (17.1\%) were ulcerative, four $(11.4 \%)$ were infiltrative, eight $(22.9 \%)$ were ulceroproliferative, three $(8.6 \%)$ were diffusely infiltrative, $13(37.1 \%)$ were ulceroinfiltrative and only one (2.9\%) case was a proliferative lesion.

Out of 35 esophagectomy cases, 30 (85.7\%) cases were of squamous cell carcinoma and five (14.3\%) were of adenocarcinoma. There was no case of adenosquamous carcinoma type in this study. Based on the tumor size, the tumors were divided into three categories. Only one $(2.9 \%)$ case was $<2 \mathrm{~cm}$ in the greatest dimension, $28(80 \%)$ cases were $2-5 \mathrm{~cm}$ in size and six $(17.1 \%)$ of the cases were $>5 \mathrm{~cm}$ in size.

Of the 35 esophagectomy specimens, majority of the cases were moderately differentiated i.e. 22 (62.9\%), eight (22.8\%) cases were well differentiated and the rest five (14.3\%) cases were poorly differentiated. The staging of the tumors was done using Tumor $(\mathrm{T})$, Node $(\mathrm{N})$ and Metastasis $(\mathrm{M})$ classification of AJCC. Out of 35 esophagectomy cases, two (5.7\%) of the cases were pT1, 14 (40\%) of the cases were pT2 and $19(54.3 \%)$ cases were pT3.

Regarding the pathological N stage 13 (37.2\%) cases were N0, 13 (37.2\%) cases were N1, one (2.9\%) of the cases were $\mathrm{N} 3$ whereas in eight (22.9\%) of the cases were $\mathrm{Nx}$ (lymph node cannot be assessed).

Out of 50 cases of esophageal carcinoma, HER-2/neu overexpression was seen in $34(68 \%)$ of the cases (Graph 9). Among the 15 endoscopic esophageal biopsies eight (53.3\%) cases displayed HER-2/neu positivity and of the 35 esophagectomy cases, seven (20\%) cases showed overexpression (score $3+$ ) of HER-2/neu, $8(22.9 \%)$ case was equivocal (score $2+), 11(31.4 \%)$ were showing $1+$ positivity and the rest nine $(25.7 \%)$ cases were negative (score 0$)$.

There was no significant association between HER-2/neu expression and the age of the patients in both esophagectomy as well as endoscopic esophageal biopsies. In esophageal resection specimen, HER-2/neu expression (score 1+ and 3+) was frequently seen in males and it was approximately two times commoner than in females both in esophagectomy and endoscopic esophageal biopsies, but there was no significant association.

Our study showed HER-2/neu positivity both in the esophageal squamous cell carcinoma and adenocarcinoma. Out of 50 cases of esophageal carcinoma 35 were esophagectomy specimens consisting of 30 cases of squamous cell carcinoma with a positivity of $22(73.34 \%)$ and five cases of adenocarcinoma with a positivity of four (80\%). 15 cases of endoscopic esophageal biopsy included 13 case of squamous cell carcinoma with a positivity of six (46.2\%) and two case of adenocarcinoma with a positivity of two (100\%) Table $1 \& 2$.

The present study showed HER-2/neu positivity in the esophageal tumors. $20(62.50 \%)$ out of 32 primary esophageal tumors located in middle $1 / 3^{\text {rd }}$ of esophagus displayed positive staining for HER-2/neu and ten $(83.34 \%)$ out of 12 primary esophageal tumors located in lower $1 / 3^{\text {rd }}$ of esophagus shows positive staining for HER-2/neu. Four (80\%) out of five GEJ tumors showed positive HER-2/neu expression. One case of esophageal tumor located in upper $1 / 3^{\text {rd }}$ of esophagus was negative for HER-2/neu staining. However, there was no significant association between HER-2/neu expression and primary tumor site.

Majority of the tumors which showed HER-2/neu expression were of the size between 2 and $5 \mathrm{cms}$ and the rest were greater than $5 \mathrm{cms}$. There was no significant association between HER-2/neu expression and the size of the tumor.

HER-2/neu positivity was noted in seven $(87.5 \%)$ out of eight ulceroproliferative lesions, nine $(69.2 \%)$ out of 13 ulceroinfiltrative lesions, four (66.7\%) out of six ulcerative lesions, 1 proliferative lesion (100\%), two $(66.7 \%)$ out of three diffusely infiltrative lesions and three $(75 \%)$ out of four infiltrative lesions. 
HER-2/neu positivity was seen in four (50\%) out of eight grade 1 tumors, 17 (77.27\%) out of 22 grade 2 tumors and five $(100 \%)$ out of five grade 3 tumors. There was no association with HER-2/neu expression and differentiation of the tumor in this study Table 3.

HER-2/neu positivity was seen in $12(85.71 \%)$ out of 14 cases of tumor invades muscularis propria (pT2) and in $14(73.68 \%$ ) out of 19 cases with tumor invades adventitia (pT3). There was a no significant association with HER-2 /neu expression and pathological tumor stage Table 4.

HER-2/neu expression was seen in $87.50 \%$ (7/8) of tumors at Nx stage, 53.84\% (7/13) at N0, 84.61\% $(11 / 13)$ at N1 stage and $100 \%(1 / 1)$ at N3 stage. However, there was no correlation between the number of lymph nodes showing metastasis and HER-2/neu expression Table 5.

In this study, HER-2/neu expression was seen in $68 \%$ of the esophageal carcinoma. However, there was no significant association with age, gender, tumor location, tumor size, histological variant, gross appearance, tumor grade, depth of invasion and nodal status.

\section{Discussion}

Esophageal squamous cell carcinoma (ESSC) still has a poor prognosis. Improving the survival of ESCC patients is a challenge for practitioners confronted with this pathology. Many options in treatment are available and remain debated among oncologists, despite the use of standardized surgical procedures and the development of promising chemotherapy.

Immunohistochemical analysis in the present study showed that $65.1 \%$ of the cases were positive for expression of HER-2/neu. Several studies reporting HER-2/neu expression in ESCC shows frequencies ranging from 0 to $64 \% .^{18-22}$ This discrepancy may have resulted due to differences in immunohistochemical protocols, different sources of antibody used by the different authors, or different criteria for evaluation of expression.

Fundamental differences in the role of HER-2/neu amplification/overexpression were found between adenocarcinoma and squamous cell carcinoma of the esophagus in this study. The findings in adenocarcinomas were very similar to breast cancer, the best examined cancer type for HER-2 alterations so far. ${ }^{23}$

It appears that the one adenocarcinoma with overexpression $(2+)$ without amplification and the two cases with amplification without overexpression may represent technical errors of immunohistochemistry based on fixation variability in routine processing of clinical samples. It is well known, that prolonged formalin fixation may disturb immunohistochemical detectability of HER-2 protein whereas incomplete fixation with consecutive tissue exposure to graded ethanol during technical processing may results in false positive HER$2 /$ neu IHC. ${ }^{24,25}$

HER-2/neu expression were less unequivocal in squamous cell carcinoma of esophagus. According to IHC staining protocol given by FDA moderate expression $(2+)$ were more frequently seen than overexpression $(3+)$. Accordingly, the interrelation between IHC positivity and amplification was less strong than in adenocarcinoma. These data fit well with observations in other squamous carcinoma types.

In present study there was no statistically significant correlation between tumor grade and HER-2/neu positivity and this is in concordance with most of the other studies. In esophageal carcinoma, TNM stage is the most important prognostic parameter in clinical practice. No correlation was found between HER-2/neu expression and $\mathrm{pT}$ or $\mathrm{N}$ factors in the present study which was in accordance with several studies. Very few studies have shown positive association with pT stage. ${ }^{26}$ Miyazono $\mathrm{F}$ et al. in his study founded, a statistically significant correlation between HER-2/neu positivity and TNM stage. ${ }^{27}$

All together, these findings indicates that HER-2/neu overexpression arise in early stages of esophageal carcinogenesis. However, because there were small number of patients in the early stage in these reports, further studies is needed to determine the interrelation between HER-2/neu expression and evolution of esophageal carcinoma.

Aggressive biological behavior such as lymphovascular invasion and lymph node metastasis, usually leads to poor prognosis. While most of the studies did not find any significant association between nodal involvement and HER-2/neu expression similar to this study, few studies have found frequent expression in cases with nodal metastasis. ${ }^{26}$

Overall HER-2/neu positivity was found in $68 \%$ (34/50) of the cases. It was noted in $74.3 \%(26 / 35)$ of the esophagectomy specimens and 53.3\% (8/15) of the endoscopic esophageal biopsy specimens. With respect to scoring of the HER-2/neu in resection specimens, HER-2/neu overexpression (score 3+) was seen in $7(20 \%)$ cases while $8(22.9 \%)$ was equivocal (score $2+$ ) and $11(31.4 \%)$ was $(1+)$ positive, the rest were negative (score $0)$. HER-2/neu expression was seen in 6 out of 7 cases $(85.7 \%)$ esophageal adenocarcinoma.

HER-2/neu overexpression or amplification ranges from $11 \%$ to $74 \%$ in esophageal adenocarcinoma. ${ }^{7,9,28-30}$ The most likely explanation for the highly variable frequency in overexpression or amplification is the difference in use of reagents and definitions of positivity. ${ }^{31}$ Safran et al 2007 shows HER- 
2/neu overexpression or amplification in $74 \%$ of the adenocarcinomas. ${ }^{29}$ The high percentage can be explained by a wider spectrum of inclusion criteria in comparison with the other studies.

Studies reporting HER-2/neu expression in ESCC show discrepant frequencies ranging from 0 to $64 \%{ }^{18-22}$ (Table 6) The reason for this large variation is multifactorial such as difference in population studied, heterogeneity of HER-2/neu expression in esophageal carcinoma, availability of only biopsy sample in advanced unresectable esophageal carcinomas, non-standardized assays using different antibodies, monoclonal vs polyclonal antibodies wherein monoclonal antibodies are highly sensitive, application of different scoring criteria which have taken varying percentage cut offs for tumor cells staining positive for HER-2/neu without taking intensity of staining in to consideration. ${ }^{32}$

Sato-Kuwabara Y et al. in their study of 185 cases of ESCC, analyzed expression of HER-2/neu according to membrane staining pattern of tumor cells;117 cases $(63.2 \%)$ were negative and $68(36.8 \%)$ were positive, of which $56(30.3 \%)$ were $2+$ and $12(6.5 \%)$ were $3+$. Statistical analysis discloses no significant association between c-erbB-2 expression and the clinicopathological findings. ${ }^{33}$

In a recent study by Yoon $\mathrm{HH}$ et al, they found highly concordant results for HER2 expression and gene amplification at the extremes of IHC scores (IHC 0, IHC 1+ or IHC3+), but not in equivocal (IHC 2+) cases, which had a $13 \%$ amplification rate. A negative IHC score (IHC 0, IHC 1+) was found to accurately predict a lack of HER-2/neu amplification in $96 \%$ of tumors, as has been shown in patients with breast cancer. $^{34,35}$ A HER-2/neu score of IHC 3+ expression was highly specific (98\%) for gene amplification. Restricting analysis to HER-2 amplified cases demonstrated a positive linear association between the level of amplification and protein expression. It is indispensable to note that the level of amplification in IHC 0 to IHC $1+$ tumors, despite being gene amplified, was low (median gene/chromosome ratio, 2.8) compared with tumors with IHC 2+ (median gene/ chromosome ratio, 5.5) or IHC 3+ (median gene/chromosome ratio, 7.9) HER2 expression. The clinical applicability of this data derives from the ToGA study, in which patients with HER-2 amplified IHC 0 to IHC $1+$ tumors did not get betterment from treatment with trastuzumab, in contrast to those with HER2-amplified IHC2+ or IHC3+ tumors, who experienced a relative risk reduction for death of $22 \%$ or $34 \%$, respectively. ${ }^{36,37}$ Our finding of low-level amplification in amplified IHC 0 to IHC 1+ cases dispense a biologic rationale for the reported lack of benefit noted with trastuzumab. The data from the current study can assist in patient selection for HER-2/neu targeted therapy by excluding patients with IHC 0 to IHC $1+$ tumors and advocating FISH assay in patients with IHC $2+$ tumors.

Learning and applying the unique criteria for assessing esophagaeal/GEJ tumors for their HER-2/neu status as defined by the ToGA investigators is a necessary and critical step in achieving the goals of providing accurate, reproducible, and reliable HER-2/neu test results for the patients, especially in advanced stages.

\section{Conclusion}

Worldwide carcinoma esophagus is coupled with considerable morbidity and mortality. Histopathology still represents the most powerful tool for esophageal carcinoma management. For years only the anatomical location of the primary lesion, its histopathological characteristics and the TNM staging guide in tailoring chemotherapy. However, in clinical practice many patients with a apparently identical tumor respond differently to the same therapy.

Various genetic alterations and well defined molecular phenotypes were concealed, which has impact on patient prognosis and response towards chemotherapy. As a result, predictive biomarkers were needed, which prognosticate treatment responses ahead of chemotherapy.

HER-2/neu protein overexpression may play a crucial role in the therapeutic management of both esophageal squamous cell carcinoma and esophagus adenocarcinoma. Inclusion of cetuximab and trastuzumab offers new benefits in patients having HER-2/neu overexpressing esophageal carcinomas and strengthen the role of pathologists in the relevant use of directed chemotherapies. This approach is promising, more valuable in responders and to avoid additional side effects in non-responders.

In present study HER-2/neu was overexpressed in both esophageal squamous cell carcinoma and esophagus adenocarcinoma. The sample size may have undermined statistical significance between HER-2/neu and grading and staging of esophageal cancers. Further studies may augment the understanding in this area, assess other clinical dimensions of HER-2/neu involvement and provide the depth impact evaluation of esophageal cancers.

\section{Reference}

[1]. Mascarello JT, Brothman AR, Davison K, Dewald GW, Herrman M, McCandless D et al. Proficiency testing for laboratories performing fluorescence in situ hybridization with chromosome-specific DNA probes. Arch Pathol Lab Med 2002; 126(12):1458. Ministerio da Saude. Secretaria de Atençao a Saude. InsitutoNacional do Cancer. Coordenaçao de Prevençao e Vigilancia.Estimativa 2005: Incidencia de Cancer no Brasil. In Estimativa2005: Incidencia de Cancer no BrasilRio de Janeiro: Rio de Janeiro: INCA; 2005 
[3]. Tachibana M, Kinugasa S, Yoshimura H, Shibakita M, Tonomoto Y, Dhar DK et al. Clinical outcomes of extended esophagectomy with three-field lymph node dissection for esophageal squamous cell carcinoma. Am J Surg 2005; 189(1):98-109.

[4]. Rowinsky EK: Signal events: Cell signal transduction and its inhibition in cancer. Oncologist 2003; 8(Suppl 3):5-17.

[5]. Roskoski R Jr: The ErbB/HER receptor protein-tyrosine kinases and cancer. BiochemBiophys Res Commun 2004; 319(1):1-11

[6]. Bhargava R, Gerald WL, Li AR, Pan Q, Lal P, Ladanyi M et al.EGFR gene amplification in breast cancer: correlation withepidermal growth factor receptor mRNA and proteinexpression and HER-2 status and absence of EGFR-activatingmutations. Mod Pathol 2005; 18(8):1027-33.

[7]. Polkowski W, van Sandick JW, Offerhaus GJ, ten Kate FJ, Mulder J, Obertop H, et al. Prognostic value of Lauren classification and c-erbB-2 oncogene overexpression in adenocarcinoma of the esophagus and gastroesophageal junction. Ann.Surg.Oncol. 1999 AprMay; 6(3):290-7.

[8]. Reichelt U, Duesedau P, Tsourlakis MC, Quaas A, Link BC, Schurr PG, et al. Frequent homogeneous HER-2 amplification in primary and metastatic adenocarcinoma of the esophagus. Mod.Pathol. 2007 Jan; 20(1):120-29.

[9]. Flejou JF, Paraf F, Muzeau F, Fekete F, Henin D, Jothy S, et al. Expression of c-erbB-2 oncogene product in Barrett' s adenocarcinoma: pathological and prognostic correlations. J.Clin.Pathol. 1994 Jan; 47(1):23-6.

[10]. Sherman CA, Turrisi AT, Wallace MB, Reed CE. Locally advanced esophageal cancer. Curr Treat Options Oncol 2002; 3:475- 85.

[11]. Gullick WJ. The type 1 growth factor receptors and their ligands considered as a complex system. EndocrRelat Cancer 2001; 8:75-82.

[12]. Harris RC, Chung E, Coffey RJ. EGF receptor ligands. Exp Cell Res 2003; 284:2- 13.

[13]. Wang SC, Hung MC. HER2 overexpression and cancer targeting. SeminOncol 2001; 28:115-24

[14]. Alitalo. K, Schwab. M. Oncogene amplification in tumor cells. Adv. Cancer Res. 1986; 47:235-81.

[15]. Brodeur GM, Seeger RC, Schwab M, Varmus. HE, Bishop JM. Amplification of N-m>r in untreated human neuroblastomas correlates with advanced disease stage. Science (Washington DC) 1984;224: 1121-24.

[16]. Rodriguez E, Rao PH, Ladanyi M, Altorki N, Albino AP, Kelsen DP et al. 11pi3-15 is a specific region of chromosomal rearrangement in gastric and esophageal adenocarcinomas. Cancer Res. 1990; 50:6410-16.

[17]. Yokota J, Yamamoto T, Miyajima N, Toyoshima K, Nomura N, Sakamoto H et al. Genetic alterations of the c-erbB-2 oncogene occur frequently in tubular adenocarcinoma of the stomach and are often accompanied by amplification of the v-erbfi homologue. Oncogene1988; 2:283-7.

[18]. Lam KY, Tin L, Ma L. C-erbB-2 protein expression in oesophageal squamous epithelium from oesophageal squamous cell carcinomas, with special reference to histological grade of carcinoma and pre-invasive lesions. Eur J SurgOncol1998; 24(5):431435.

[19]. Friess H, Fukuda A, Tang WH, Eichenberger A, Furlan N, Zimmermann A et al. Concomitant analysis of the epidermal growth factor receptor family in esophageal cancer: overexpression of epidermal growth factor receptor mRNA but not of c-erbB-2 and cerbB-3. World J Surg 1999; 23(10):1010-18

[20]. Hardwick RH, Barham CP, Ozua P, Newcomb PV, Savage P, Powell R et al. Immunohistochemical detection of p53 and cerbB-2 in oesophageal carcinoma; no correlation with prognosis. Eur J SurgOncol1997; 23(1):30-5.

[21]. Suo Z, Su W, Holm R, Nesland JM: Lack of expression of c-erbB-2 oncoprotein in human esophageal squamous cell carcinomas. Anticancer Res 1995; 15(6B):2797-8

[22]. Suwanagool P, Parichatikanond P, Maeda S: Expression of c-erbB-2 oncoprotein in primary human tumors: an immunohistochemistry study. Asian Pac J Allergy Immunol1993; 11(2):119-22.

[23]. Zhang D, Salto-Tellez M, Do E. Evaluation of HER-2/neu oncogene status in breast tumors on tissue microarrays. Hum Pathol 2003; 34:362-8

[24]. Tapia C, Schraml P, Simon R. HER2 analysis in breast cancer: reduced immunoreactivity in FISH non-informative cancer biopsies. Int J Oncol 2004; 25:1551- 7 .

[25]. Mirlacher M, Kasper M, Storz M. Influence of slide aging on results of translational research studies using immunohistochemistry. Mod Pathol 2004; 17:1414- 20.

[26]. Mimura K, Kono K, Hanawa M, Mitsui F, Sugai H, Miyagawa N et al. Frequencies of HER-2/neu expression and gene amplification in patients with oesophageal squamous cell carcinoma. Brit J Cancer 2005; 92:1253 - 1260.

[27]. Miyazono F, Metzger R, Warnecke-Eberz U, Baldus SE, Brabender J, Bollschweiler E, et al. Quantitative c-erbB-2 but not c-erbB-1 mRNA expression is a promising marker to predict minor histopathologic response to neoadjuvant radiochemotherapy in oesophageal cancer . Brit J Cancer 2004 ;91: 666 - 72.

[28]. Safran H, DiPetrillo T, Nadeem A, Steinhof M, Tantravahi U, Rathore R etal. Trastuzumab, paclitaxel, cisplatin, and radiation for adenocarcinomaof the esophagus: a phase I study. Cancer Invest. 2004; 22(5):670-7.

[29]. Safran H, Dipetrillo T, Akerman P, Ng T, Evans D, Steinhof M et al. PhaseI/II study of trastuzumab, paclitaxel, cisplatin and radiation for locally advanced, HER/2 overexpressing, esophageal adenocarcinoma. Int J Radiat Oncol Biol Phys 2007 Feb 1 ; 67(2):405-9.

[30]. Hardwick RH, Shepherd NA, Moorghen M, Newcomb PV, Alderson D.c-erbB-2 overexpression in the dysplasia/carcinoma sequence of Barrett' s oesophagus. J.Clin.Pathol. 1995 Feb; 48(2):129-32.

[31]. Sunpaweravong P, Sunpaweravong S, Puttawibul P, Mitranun W, Zeng C, Baron A E, et al. Epidermal growth factor receptor and cyclinD are independently amplified and overexpressed in esophageal squamous cell carcinoma. J Cancer Res clinOncol 2005; 131:111-9.

[32]. Shan L, Ying J, Lu N. HER2 expression and relevant clinicopathological features in gastric and gastroesophageal junction adenocarcinoma in a Chinese population. DiagnPathol 2013; 8:76

[33]. Sato-Kuwabara Y, Neves J, Fregnani J HTG, Sallum R A, Soares F A.Evaluation of gene amplification and protein expression ofHER-2/neu in esophageal squamous cell carcinoma using Fluorescence in situ Hybridization (FISH) and immunohistochemistry. BMC Cancer 2009; 9:6.

[34]. Wolff AC, Hammond ME, Schwartz JN. American Society of clinical oncology/College of American Pathologists guidelines recommendations for human epidermal growth factor 2 testing in breast cancer. J ClinOncol 2007; 25:118-45.

[35]. Yaziji H, Goldstein LC, Barry TS. HER-2 testing in breast cancer using parallel tissue-based methods. JAMA. 2004; 291:1972- 7.

[36]. Bang YJ, VanCutsem E, Feyereislova A. ToGA Trial Investigators. Trastuzumab in combination with chemotherapy versus chemotherapy alone for treatment of HER2-positive advanced gastric or gastro-oesophageal junction cancer (ToGA): a phase 3, open-label, randomised controlled trial. Lancet. 2010; 376:687-97.

[37]. National Cancer Institute. FDA Approval for Trastuzumab: HER2 overexpressing Metastatic Gastric or Gastroesophageal (GE) Junction Adenocarcinoma. cancer.gov/cancertopics/druginfo/ fda-trastuzumab. 


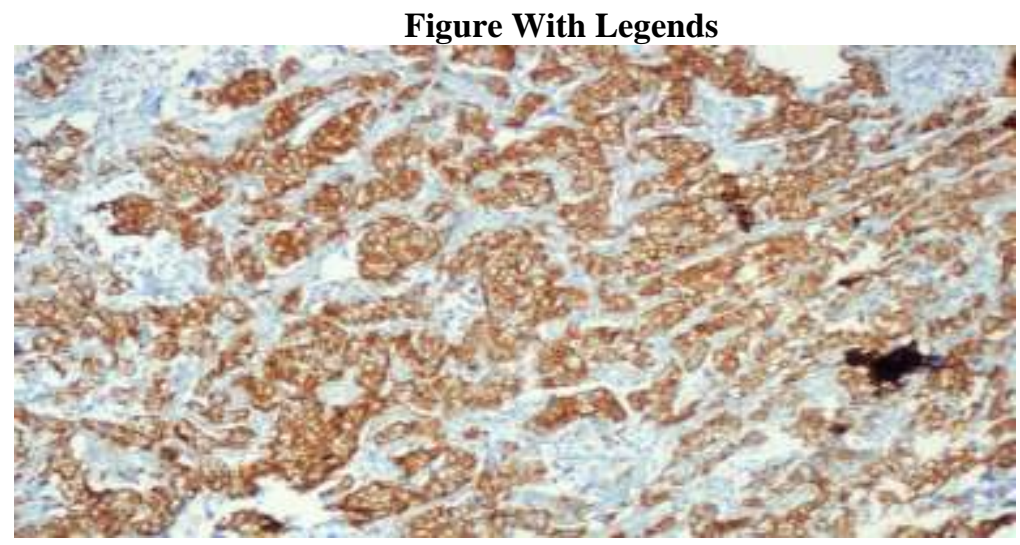

Fig 5- HER-2/neu IHC positive control (carcinoma breast) score 3+ with distinct strong membrane staining $(\mathrm{x} 40)$

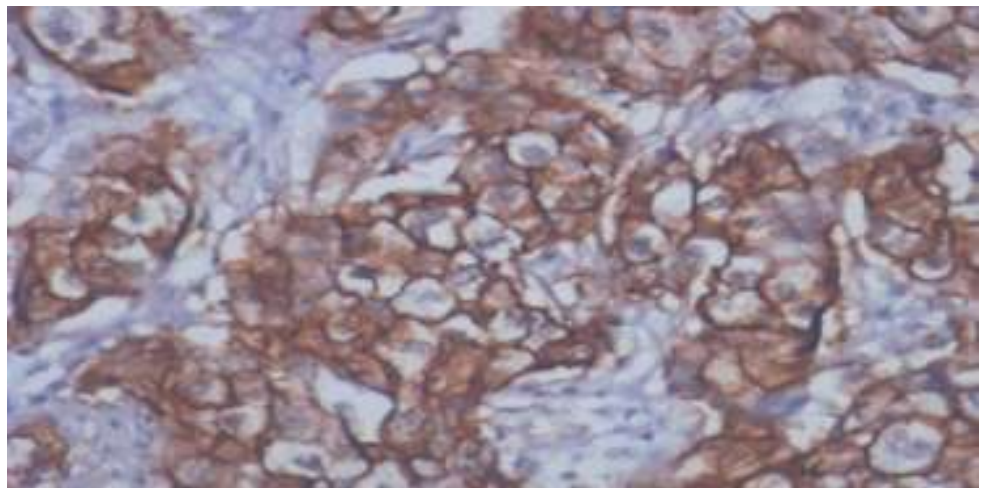

Fig 6: HER-2/neu IHC positive control (breast carcinoma) showing strong, complete membrane stating $3+(x 200)$

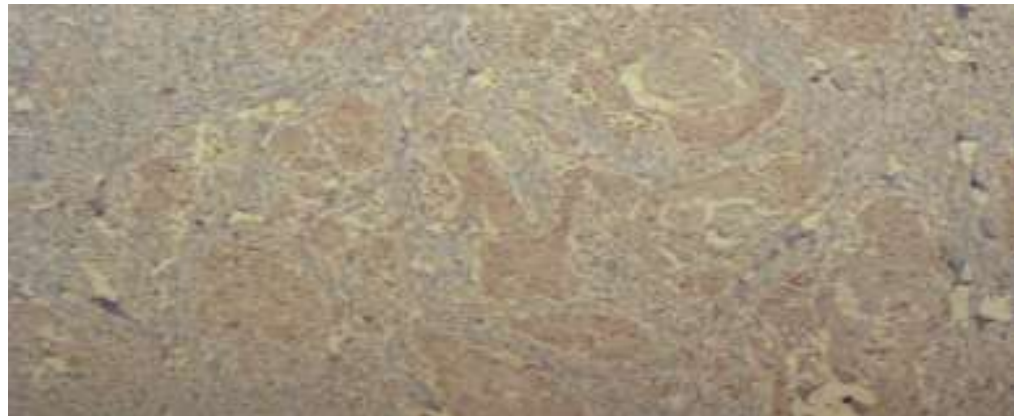

Fig 21: HER-2/neu IHC score 1+ showing incomplete membranous staining in $>10 \%$ of the tumor cells in esophageal squamous cell carcinoma (x100)

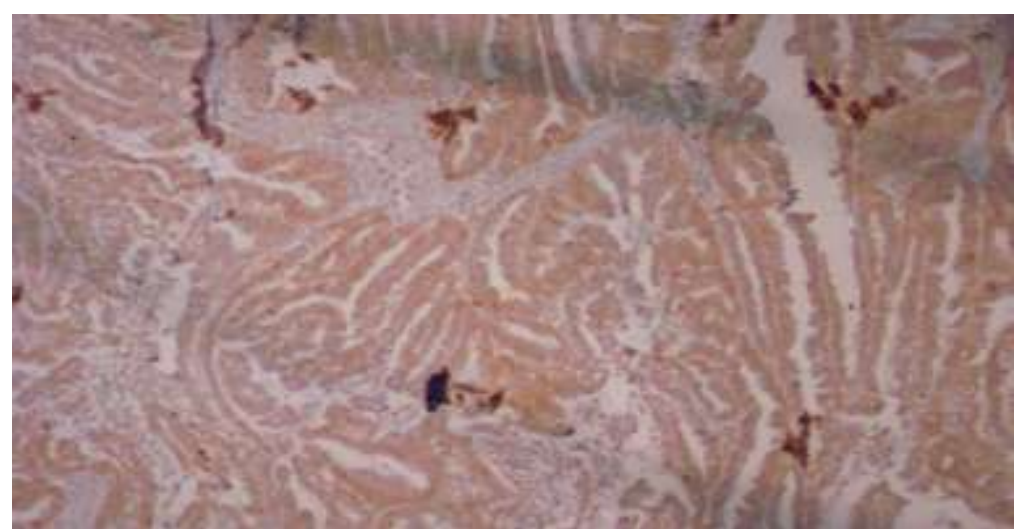

Fig 8: HER-2/neu IHC score 2+ showing weak to moderate complete membranous staining in $>10 \%$ of the tumor cells in moderately differentiated adenocarcinoma(x40) 


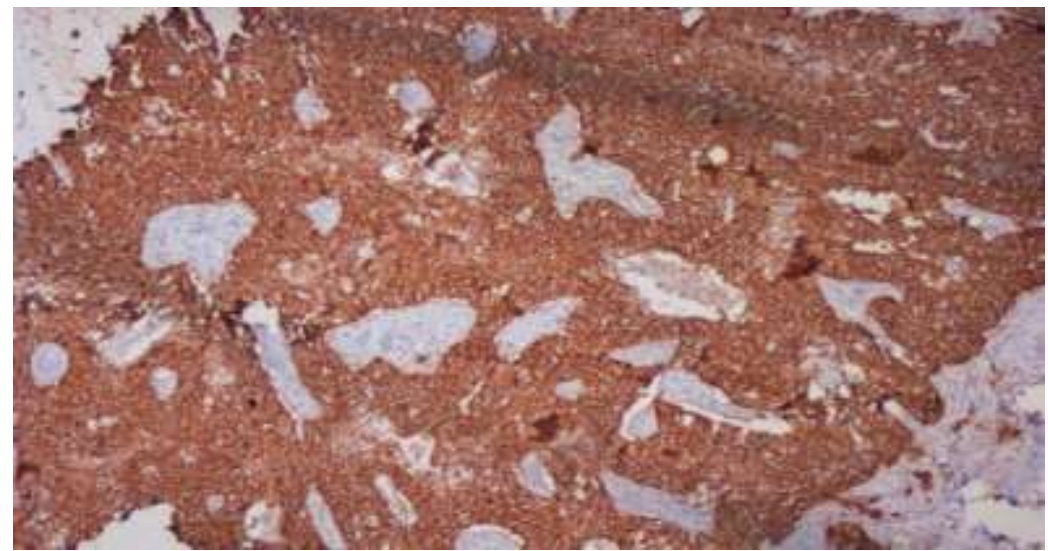

Fig 14: HER-2/neu IHC score 3+ showing strong complete membranous staining in $>10 \%$ of the tumor cells in poorly differentiated Esophageal squamous cell carcinoma $(\mathbf{x 4 0})$

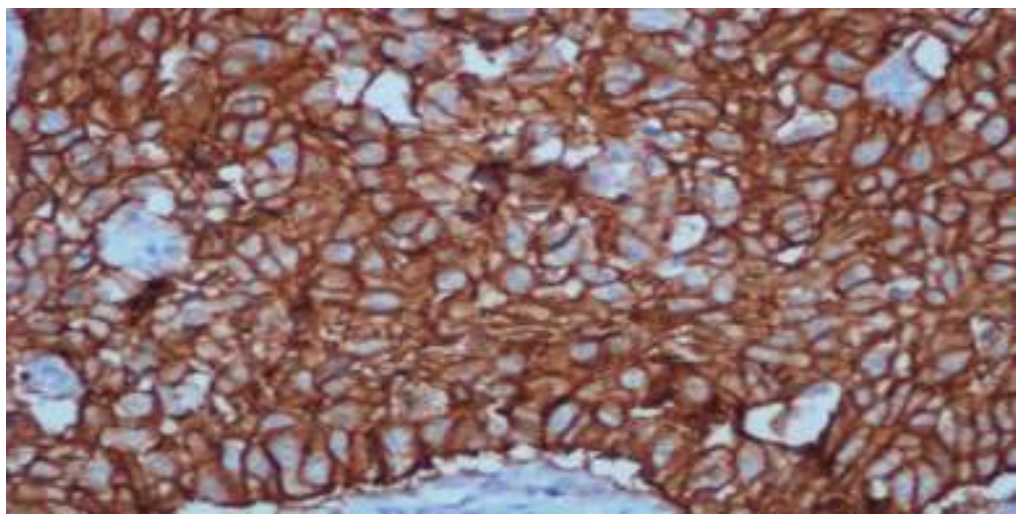

Fig 16: HER-2/neu IHC score 3+ showing strong complete membranous staining in $>10 \%$ of the tumor cells in poorly differentiated Esophageal squamous cell carcinoma (x200)

Tables

Table 1: HER-2/neu expression in esophagectomy- ESCC and Adenocarcinoma $(n=35)$

\begin{tabular}{|c|c|c|c|c|c|}
\hline & \multicolumn{4}{|c|}{ HER-2/neu status } & \multirow[b]{2}{*}{ Total } \\
\hline & Score 0 & Score 1+ & Score 2+ & Score 3+ & \\
\hline $\begin{array}{l}\text { Squmaous cell carcinoma } \\
\text { Adenocarcinoma }\end{array}$ & $\begin{array}{l}8 \\
\\
\end{array}$ & $\begin{array}{l}10 \\
1\end{array}$ & 6 & $\begin{array}{l}6 \\
1\end{array}$ & $\begin{array}{l}30 \\
05\end{array}$ \\
\hline TOTAL & 9 & 11 & 8 & 7 & 35 \\
\hline
\end{tabular}

Table 2: HER-2/neu expression in endoscopic esophageal biopsies- ESSC and Adenocarcinoma $(\mathrm{n}=15)$

\begin{tabular}{|l|l|l|l|l|l|}
\hline & HER-2/neu status & \multirow{2}{*}{ Total } \\
\cline { 2 - 6 } & Score 0 & Score 1+ & Score 2+ & Score 3+ & \\
\hline Squmaous cell carcinoma & 7 & 6 & 0 & 0 & 13 \\
Adenocarcinoma & 0 & 1 & 0 & 1 & 02 \\
\hline \multirow{2}{*}{ TOTAL } & $\mathbf{7}$ & $\mathbf{7}$ & $\mathbf{0}$ & $\mathbf{1}$ & $\mathbf{1 5}$ \\
\hline
\end{tabular}

Table 3: HER-2/neu expression based on tumor grade in esophagectomy $(n=35)$

\begin{tabular}{|l|c|c|c|c|l|}
\hline & \multicolumn{2}{|l|}{ HER-2/neu status } & \\
\cline { 2 - 5 } Tumor grade & Score 0 & Score 1+ & Score 2+ & Score 3+ & Total \\
\hline Well differentiated & 4 & 2 & 2 & 0 & 8 \\
Moderately differentiated & 5 & 7 & 5 & 5 & 22 \\
Poorly differentiated & 0 & 2 & 1 & 2 & 5 \\
\hline Total & $\mathbf{9}$ & $\mathbf{1 1}$ & $\mathbf{8}$ & $\mathbf{7}$ & $\mathbf{3 5}$ \\
\hline
\end{tabular}


A Study Of Evaluation of Immunoreactivity of C-Erbb-2 And Histopathological Parameter...

Table 4: HER-2/neu expression based on pT stage of tumor in esophagectomy $(n=35)$

\begin{tabular}{|c|c|c|c|c|c|}
\hline \multirow[b]{2}{*}{ Tumor stage } & \multicolumn{4}{|c|}{ HER-2/neu status } & \multirow[b]{2}{*}{ Total } \\
\hline & Score 0 & Score 1+ & Score 2+ & Score 3+ & \\
\hline T1 & 2 & 0 & 0 & 0 & 2 \\
\hline $\mathrm{T} 2$ & 2 & 6 & 5 & 1 & 14 \\
\hline T3 & 5 & 5 & 3 & 6 & 19 \\
\hline Total & 9 & 11 & 8 & 7 & 35 \\
\hline
\end{tabular}

Table 5: HER-2/neu expression based on nodal status in esophagectomy $(n=35)$

\begin{tabular}{|l|c|l|l|c|c|}
\hline \multirow{2}{*}{ Lymph node stage } & HER-2/neu status & \multicolumn{2}{c|}{} \\
\cline { 2 - 6 } Score 0 & Score 1+ & Score 2+ & Score 3+ & Total \\
\hline Nx & 1 & 3 & 1 & 3 & 8 \\
N0 & 6 & 1 & 5 & 1 & 13 \\
N1 & 2 & 7 & 2 & 2 & 13 \\
N2 & 0 & 0 & 0 & 0 & 0 \\
N3 & 0 & 0 & 0 & 1 & 1 \\
\hline Total & $\mathbf{9}$ & $\mathbf{1 1}$ & $\mathbf{8}$ & $\mathbf{7}$ & $\mathbf{3 5}$ \\
\hline
\end{tabular}

Table 6: Comparison of frequency of HER-2/neu expression with other studies

\begin{tabular}{|l|l|l|}
\hline Study & No. of cases & Her2/neu expression \\
\hline K Mimura et al & 66 & $30.3 \%$ \\
\hline Yukie Sato-Kuwabara et al & 185 & $36.8 \%$ \\
\hline Y Kawaguchi et al & 66 & $31.0 \%$ \\
\hline Safran et al & 36 & $33.0 \%$ \\
\hline Safran et al & 19 & $74.0 \%$ \\
\hline Flejou et al & 66 & $11.0 \%$ \\
\hline Polkowski et al & 41 & $24.0 \%$ \\
\hline Reichelt et al & 110 & $15.0 \%$ \\
\hline Hardwick et al & 31 & $26.0 \%$ \\
\hline Phillips et al & 136 & $24.0 \%$ \\
\hline Tanner et al & 100 & $24.0 \%$ \\
\hline Present study & 50 & $68.0 \%$ \\
\hline
\end{tabular}

